\title{
Longitudinal Study of Fetal Body Movements: Nomograms, Intrafetal Consistency, and Relationship with Episodes of Heart Rate Patterns $A$ and $B$
}

\author{
JUDITH TEN HOF, ILSE J.M. NIJHUIS, EDU J.H. MULDER, JAN G. NIJHUIS, HARINI NARAYAN, \\ DAVID J. TAYLOR, PAUL WESTERS, AND GERARD H.A. VISSER \\ Department of Obstetrics and Gynaecology, University Hospital of Utrecht, Utrecht, The Netherlands \\ [J.t.H., I.J.M.N., E.J.H.M., G.H.A.V.]; and Department of Obstetrics and Gynaecology, University \\ Hospital of Maastricht, Maastricht, The Netherlands [J.G.N.]; Princess Margaret Hospital, Swindon, U.K. \\ [H.N.]; University Hospital of Leicester, Leicester, U.K. [D.J.T.]; the Centre for Biostatistics, University \\ of Utrecht, Utrecht, The Netherlands [P.W.]
}

\begin{abstract}
Our objective was to investigate the longitudinal development of incidence parameters of fetal body movements to define normal reference ranges, to relate them to episodes of fetal heart rate patterns $\mathrm{A}$ and $\mathrm{B}$, and to determine the intrafetal consistency for these parameters. Twenty-nine fetuses were studied longitudinally from 24 wk of gestation. Fetal body movements and heart rate were recorded at fortnightly intervals between 24 and $36 \mathrm{wk}$ of gestation and weekly from 36 wk of gestation. Data were analyzed using multilevel analysis. Reference ranges were constructed for the percentage of observation time that movements were present, the number of movement bursts per hour, the mean burst duration, and the median onset-onset interval. The median percentage incidence of fetal body movements decreased from $17 \%$ at $24 \mathrm{wk}$ to about $7 \%$ near term. The developmental course was the same during active episodes. Body movements also
\end{abstract}

ABSTRACT decreased during episodes of relative quiescence, in the course of pregnancy. Intrafetal variance was on average $40-80 \%$ of the total range of the four movement parameters. Normal reference ranges were developed for incidence parameters of fetal body movements from $24 \mathrm{wk}$ of gestation onward. The overall decline in the incidence of movements during pregnancy appeared to be a developmental phenomenon and not due to progressively increasing episodes of fetal quiescence. Individual fetuses showed a degree of consistency in the percentage incidence of body movements, but intra- and interfetal variances were generally high, resulting in wide ranges. (Pediatr Res 52: 568-575, 2002)
FHR, fetal heart rate
Abbreviations
FHRP, fetal heart rate pattern

The majority of neurodevelopmental disabilities have been estimated to originate from prenatal factors (1). Both the quantity and quality of fetal body movements have been recognized as important indicators of fetal well being and of the integrity of the CNS $(2,3)$. Studying fetal body movements could therefore provide a key to elucidate the prenatal etiology and pathogenesis of abnormal neuromotor development, which might, eventually, facilitate early intervention and optimal treatment before, during, and after birth. There is evidence that the quality of fetal body movements is more likely an indicator

Received January 20, 2001; accepted November 21, 2001

Correspondence: J. ten Hof, Ph.D., Department of Obstetrics and Gynaecology, KE.04.123.1, University Medical Center, Lundlaan 6, 3584 EA Utrecht, The Netherlands; e-mail: tenhof@yahoo.com

Supported by a grant from the Commission of the European Communities (Contract No. CHRX-CT 94-0613).

DOI: 10.1203/01.PDR.0000030881.20888.74 of brain integrity than the quantity of movements $(4,5)$. However, before either of the two can be used as such in clinical practice, the normal developmental course and its possible sources of variation must be defined. This requires the use of a prospective longitudinal study design (6). In the present study, we focused on the developmental course of various quantitative aspects of fetal body movements.

Several authors have reported on the incidence of fetal body movements. However, because of the absence of a uniform definition of a body movement, and differences in study design (longitudinal or cross-sectional) and data analysis, the reported mean/median values and ranges of normality differ greatly among the various studies (7-16), as we have recently described (17). Moreover, there is still some controversy regarding whether the movement incidence does or does not decline with advancing gestation. The emergence of episodes of fetal quiescence in the course of the third trimester has been thought 
to explain the decrease in fetal body movements observed by some authors $(7,10,14)$ but not by others $(8,11,13,16,18)$. It may be postulated that the amount of movement during active episodes remains constant over time, whereas the overall incidence decreases due to the development of prolonged episodes of fetal quiescence.

In recent studies of FHR and its variation, we found large interindividual differences, but a remarkable consistency as to the level and trend over time of these parameters within individual fetuses $(19,20)$. De Vries et al. $(7,10,14)$ found a rather low tendency toward intrafetal consistency in fetal activity in 12 low-risk fetuses. Other data addressing inter- and intrafetal consistency are lacking. The aims of this study were 1) to investigate the longitudinal development of incidence parameters of fetal body movements to define normal reference ranges; 2) to assess these incidence parameters in relation to episodes of FHRP A and B; and 3) to determine whether these parameters show intrafetal consistency.

\section{SUBJECTS AND METHODS}

Twenty-nine women with a singleton pregnancy participated in a longitudinal study of fetal behavioral development between 24 wk of gestation and term. Written informed consent was obtained and the study was approved by the local ethical committee. Data were collected between 1995 and 1997. Gestational age was calculated from the first day of the last menstrual period or from an ultrasound scan early in pregnancy. A routine ultrasound scan performed at 18-20 wk detected no abnormalities in any of the fetuses. None of the women were on any medication. Eleven women were nulliparous. All infants were delivered after $36 \mathrm{wk}$ of gestation without signs of fetal distress. Mean gestational age at birth was 39 wk (range 36-41 wk) and mean birth weight was $3290 \mathrm{~g}$ (range $2665-4500 \mathrm{~g}$ ). Birth weights were all above the 10th percentile for gestational age according to customized growth charts (21). Sixteen baby girls and 13 baby boys were healthy at birth. One of the baby girls was born with Peters' anomaly, an opacity of the eye lenses that will impair her vision (22). She was not excluded on the assumption that this isolated abnormality does not affect fetal behavioral development. Separate analysis of her data showed that all values were within the normal ranges. Neurologic examinations carried out by a pediatrician in the first week after birth and at 3 mo of age revealed no abnormalities in any of the infants other than the eye abnormality.

For an adequate assessment of fetal motility, sufficiently long observations are necessary. Ultrasound observations of fetal body movements were made for $60 \mathrm{~min}$ at biweekly intervals between 24 and $36 \mathrm{wk}$ of gestation and for $120 \mathrm{~min}$ weekly from $36 \mathrm{wk}$ until delivery, to account for prolonged periods of fetal quiescence with the development of fetal behavioral states. We felt it was safe to perform this study, as previous studies could not show adverse fetal outcome or long-term effects associated with the use of diagnostic ultrasound during pregnancy (23-26). This is in accordance with statements by the American Institute of Ultrasound in Medicine Bioeffects Committee (AIUM) and the European Federa- tion of Societies for Ultrasound in Medicine and Biology (EFSUMB) (27-30). Furthermore, a study of the AIUM in 1976 did not show any significant effects in mammalian tissues exposed to intensities below $100 \mathrm{~mW} / \mathrm{cm}^{2}$ (27). For ultrasonic exposure times between 1 and $500 \mathrm{~s}$, no hazardous or harmful side effects could be found even when the product of intensity and exposure time was $50 \mathrm{~J} / \mathrm{cm}^{2}$. Comparable to de Vries et al. (31), we calculated that, although the exposure time exceeded $500 \mathrm{~s}$, the product of intensity and exposure time would not exceed $2.9 \mathrm{~J} / \mathrm{cm}^{2}$ (assuming a spatial peak temporal average of $0.2 \mathrm{~mW} / \mathrm{cm}^{2}$ ) in our recordings with two transducers for 1 or $2 \mathrm{~h}$.

All recordings were carried out in the Leicester General Hospital, in a quiet separate room, between 0900 and $1900 \mathrm{~h}$. They were standardized for the time of the day in each woman and the women did not smoke or eat for at least $1 \mathrm{~h}$ before the recording. The women lay in a semi-recumbent position. Each fetus was visualized in a parasagittal plane using a real-time linear array ultrasound scanner (model SSD 650, Aloka Co., Tokyo, Japan; probe $3.5 \mathrm{MHz}$ curvilinear) and was scored by the same observer throughout the study period to reduce interobserver effects. Before data collection, intra- and interobserver agreement was assessed. Based on $10 \mathrm{~h}$ of observation, the weighed kappa coefficient was $0.90-0.92$ and 0.88 , respectively $(32,33)$. With the transducer in this position, most of the fetal head, trunk, part of the abdomen, and one or more limbs could be viewed. Fetal body movements comprise a complex variable pattern, involving movements of the body, limbs, and head in a random order, as can also be observed in the neonate (34). This motor pattern has also been referred to as fetal general movements, trunk movements, or rolling and stretching $(8,10-15)$. Clearly distinctive movement patterns as hiccups, breathing, eye, and isolated head or limb movements were excluded. Startles and stretches may have been included. However, beyond 24 wk they occur occasionally and their number and percentage incidence constitute no substantial contribution to the total number and percentage incidence (14, 31). All fetal body movements, including shorter lasting bursts $(<2 \mathrm{~s})$, were marked online on an event recorder (model Uniscript UD210, Picker Schwarzer, Munich, Germany; paper speed $1 \mathrm{~mm} / \mathrm{s}$ ), using hand-held push buttons. The button was pressed for as long as the movement was observed. The information was fed simultaneously into a personal computer running a program specially designed for fetal behavioral data acquisition and analysis (Poly version 5.0; Inspektor Research Systems, Amsterdam, The Netherlands). Movements that occurred within $1 \mathrm{~s}$ apart were considered as a single burst of movement. For each recording, the number of bursts per hour, the percentage of observation time that movements were present for, the mean burst duration, and the median onsetonset interval were calculated.

Multilevel analysis was performed with the software program Mln (Multilevel model project, London, U.K.) to construct nomograms (medians and the 2.5th and 97.5th centiles) for the above-mentioned movement parameters. Multilevel analysis allows for dependency of measurements in hierarchically structured data, whereas traditional regression analysis presupposes the independence of observations (35). Another 
Table 1. Equations for the lines of ${ }^{10} \log$ (percentage), ${ }^{10} \log$ (number), duration and ${ }^{10} \log$ (interval) with gestation, including interfetal and

\begin{tabular}{|c|c|c|c|c|c|c|c|c|}
\hline Parameter & $\begin{array}{l}{ }^{10} \log (\text { percentage }) \\
\text { estimate }\end{array}$ & SE & $\begin{array}{c}{ }^{10} \log (\text { number }) \\
\text { estimate }\end{array}$ & SE & $\begin{array}{l}\text { Duration } \\
\text { estimate }\end{array}$ & SE & $\begin{array}{c}{ }^{10} \log (\text { interval }) \\
\text { estimate }\end{array}$ & SE \\
\hline \multicolumn{9}{|l|}{ Fixed } \\
\hline Constant (b) & 1.235 & 0.03866 & 2.283 & 0.01717 & 3.033 & 0.1489 & 0.9485 & 0.01541 \\
\hline$a_{2}$ & 0.001164 & 0.0005132 & & & & & -0.0007006 & 0.000346 \\
\hline \multicolumn{9}{|l|}{ Random } \\
\hline \multicolumn{9}{|l|}{$\begin{array}{l}\text { Level } 2 \\
\quad \text { (Interf }\end{array}$} \\
\hline $\mathrm{c}_{1}$ & -0.0004888 & 0.0006105 & -0.00004349 & 0.0002384 & -0.01138 & 0.0148 & -0.0001321 & 0.0001826 \\
\hline $\mathrm{c}_{2}$ & 0.0001213 & 0.00006931 & 0.00007672 & 0.00004002 & 0.003869 & 0.001849 & 0.00006561 & 0.0000332 \\
\hline \multicolumn{9}{|c|}{$\begin{array}{l}\text { Level } 1 \\
\quad \text { (Intrafetal variance) }\end{array}$} \\
\hline Constant (d) & 0.02505 & 0.002625 & 0.00504 & 0.002021 & 0.7868 & 0.1403 & 0.00195 & 0.001296 \\
\hline $\mathrm{d}_{1}$ & & & 0.0007176 & 0.0001598 & -0.01448 & 0.005951 & 0.0008704 & 0.0001381 \\
\hline
\end{tabular}

All equations must be read as $\mathrm{y}=\mathrm{b}+\mathrm{a}_{1}(\mathrm{WGA}-24)+\mathrm{a}_{2}(\mathrm{WGA}-24)^{2}$. The equation for the interfetal variance is $\mathrm{y}=\mathrm{c}+2 \mathrm{c}_{1}\left(\right.$ WGA-24) $+\mathrm{c}_{2}\left(\right.$ WGA-24) ${ }^{2}$. The equation for the intrafetal variance is $\mathrm{y}=\mathrm{d}+2 \mathrm{~d}_{1}$ (WGA-24). SE, standard error; WGA, weeks gestational age.

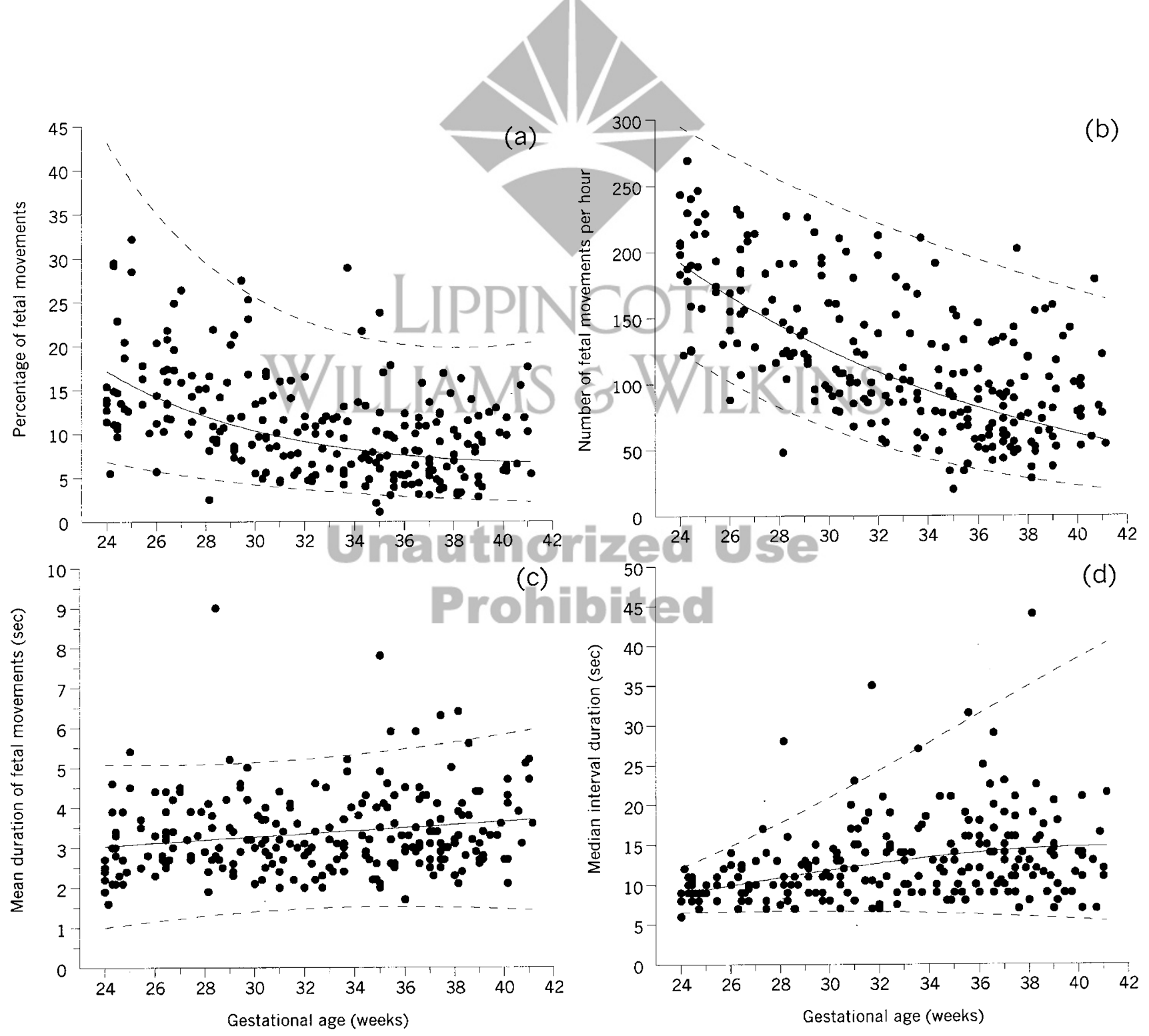

Figure 1. Nomograms of the four incidence parameters of fetal body movements. Presented are the median (solid line), 2.5th and 97.5th centiles (dashed lines), and individually measured values in relation to gestational age for $(a)$ the percentage of time spent making body movements, $(b)$ the number of body movements per hour $(c)$ and their mean duration, and $(d)$ the median onset-onset interval. 

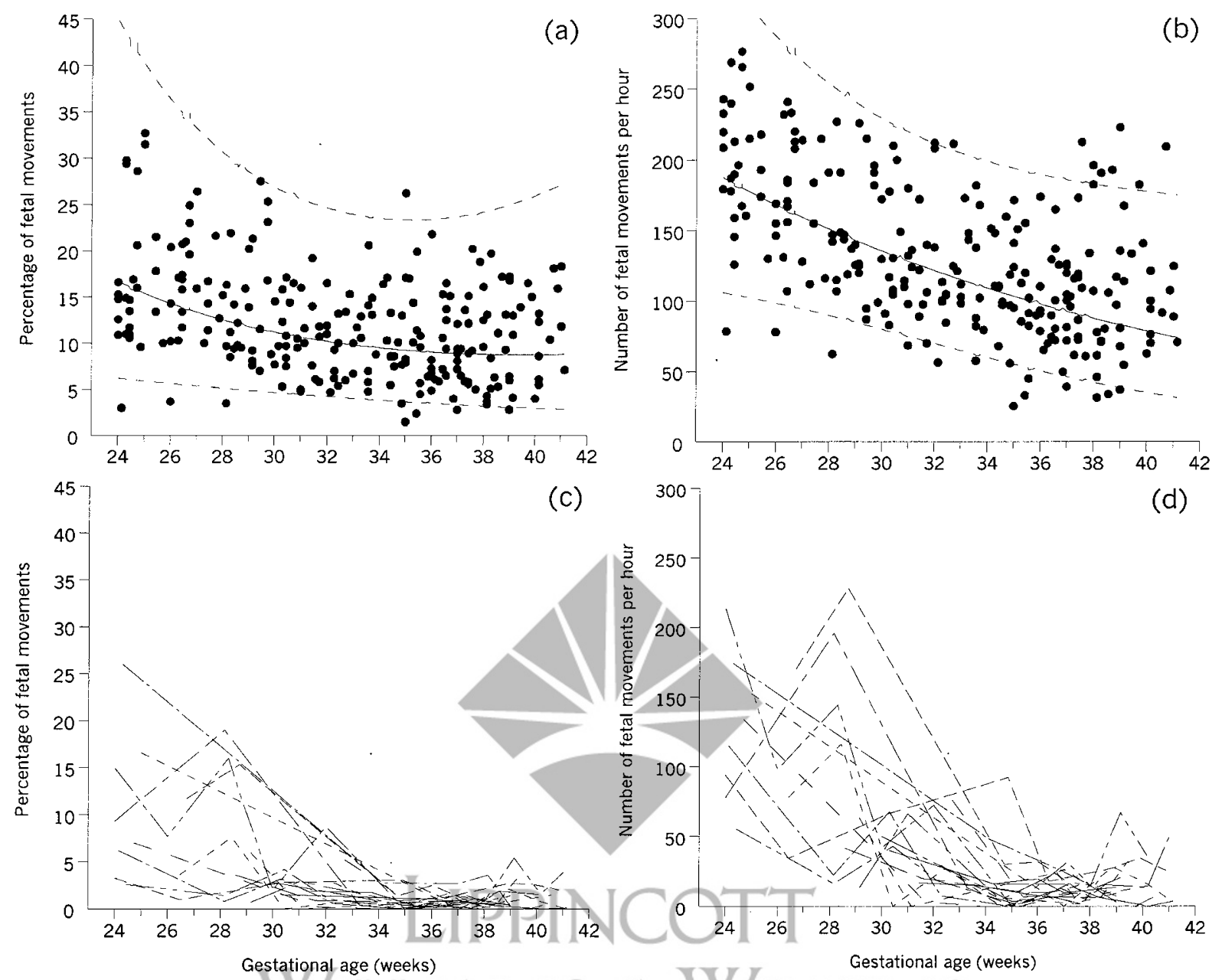

Figure 2. Incidence of fetal body movements during episodes of FHRP A and B in relation to gestational age. The percentage incidence of body movements $(a)$ and the number of movements per hour (b) during episodes of FHRP B are presented by nomograms (medians and 2.5th and 97.5 th centiles) and individually measured values. For episodes of FHRP A, these incidence parameters are shown for individual fetuses with five or more recordings during the study period ( $n$ $=19)$ in $(c)$ and $(d)$. (See text for explanation of differential data presentation.)

advantage of this technique is that it can deal with any pattern and frequency of measurement. Repeated measures are an example of a two-level hierarchy, with measurement repetitions as level 1 units and subjects as level 2 units. The Mln program calculates a fixed part (intercept and regression coefficient) and a random part (intra- and interfetal variance). Further explanatory variables can be included in the analysis at the measurement level and the subject level. Different models are compared with a maximum likelihood procedure. The difference in likelihood can be tested for significance.

In our study, the recordings made at different gestational ages in the same fetus represented the level 1 units and the different fetuses the level 2 units. So, the random parts at level 1 and level 2 were intrafetal and interfetal variance, respectively. All movement parameters were tested for the possible influence of time of the day at which the recording took place on the intercept of the model and for parity on the intercept and regression coefficient. For gestational age, both linear and quadratic contributions to the model were tested. To obtain normally distributed data, logarithmic transformation was performed for the percentage and number of movements and the median onset-onset interval. The best fitting model was cho- sen for each of the four movement parameters to calculate the $95 \%$ confidence interval for each fetus. Regression lines were drawn for each fetus to investigate the individual relationship between a particular parameter and gestational age.

Fetal behavioral states develop during pregnancy and are almost always present from 36 wk of gestation onward (36). They are identified by the coincidence of specific combinations of FHRP with presence or absence of body movements and eye movements (36). Linkage of pairs of state variables can already be found at $30-32$ wk of gestation before true states can be identified (36-40). Because we studied pregnancies from 24 wk gestation onward and as we did not include eye movements, the state concept was not applicable. Previous studies have shown an association between rest activity cycles and FHRP from 28 wk onward $(41,42)$. We chose to use the FHRP $\mathrm{A}$ and $\mathrm{B}$ as indicators of periods of fetal rest and activity, respectively.

FHR was monitored with a cardiotocograph (Hewlett Packard 8040A, Böblingen, Germany). FHR tracings were visually classified into episodes of FHRP A, B, C, or D, using predefined criteria $(36,43)$. FHRP A is a stable heart rate, with a narrow oscillation bandwidth. Isolated accelerations occur that 

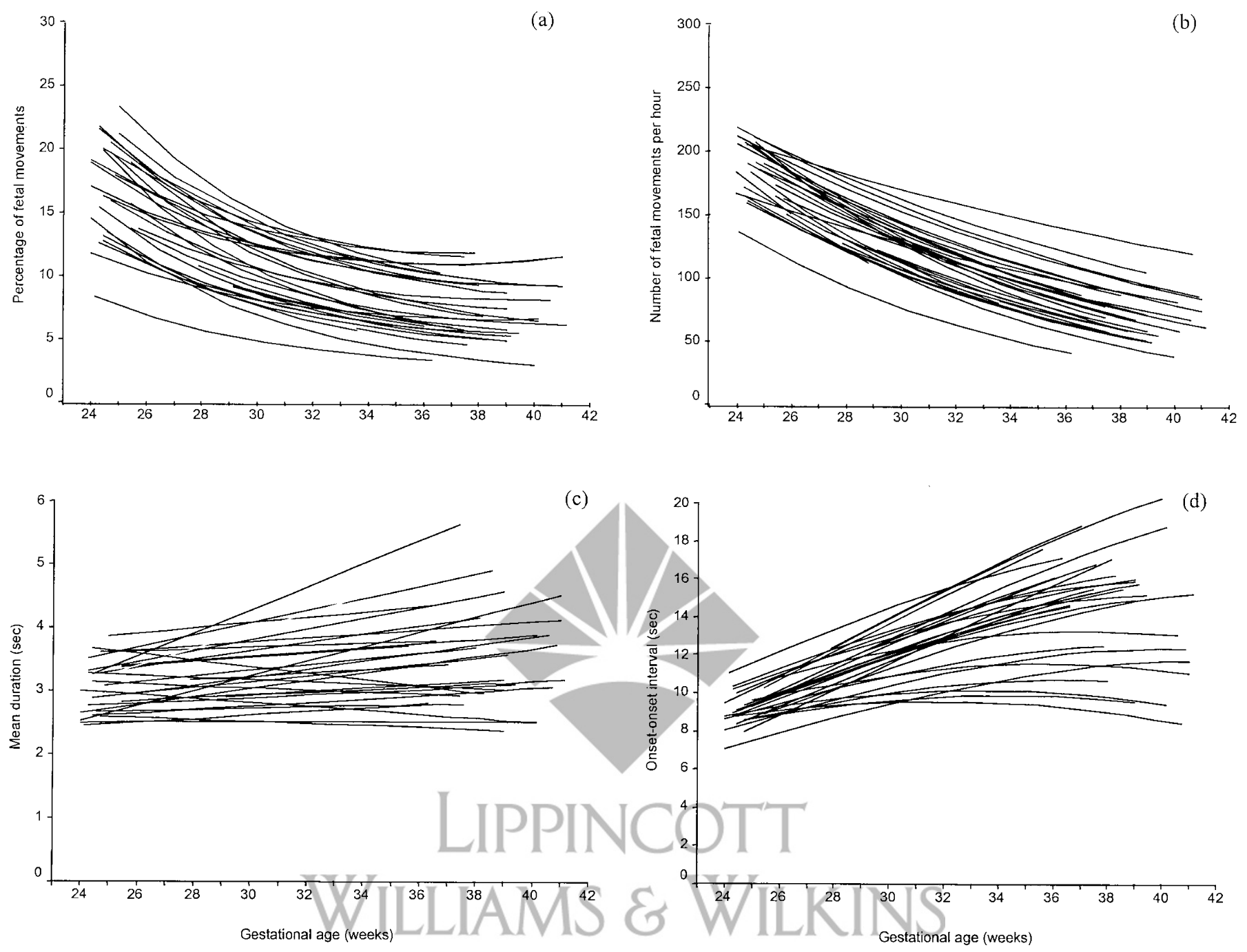

Figure 3. Regression lines for each of the 29 fetuses, as calculated by multilevel analysis, for the percentage of body movements (a), the number of body movements per hour $(b)$ and their mean duration $(c)$, and median onset-onset interval $(d)$

are strictly related to body movements. FHRP B has a wider oscillation bandwidth with frequent accelerations during movements. FHRP C is stable, with a wider oscillation bandwidth than pattern $\mathrm{A}$ and there are no accelerations. FHRP D is unstable, with large and long-lasting accelerations, which are frequently fused into a sustained tachycardia. The percentage incidence and the number of movements per hour during episodes of FHRP B were analyzed by multilevel analysis. Episodes of FHRP A were scarce, especially before $32 \mathrm{wk}$. After $32 \mathrm{wk}$, there were no movements at all during episodes of FHRP A in a number of recordings. Multilevel analysis was not feasible for these two reasons. Instead, individual curves were constructed for fetuses with five or more recordings containing FHRP A episodes.

\section{RESULTS}

Reference ranges of movement parameters. A total of 238 recordings was obtained and each woman contributed an average of eight recordings (range 4-11). The time of day of recording and parity had no significant effect on any of the movement parameters.
For the percentage incidence of body movements and the onset-onset intervals, the goodness of fit improved significantly by adding a quadratic component of gestational age to the models. The equations of all models are given in Table 1. The nomograms with median values and reference ranges (2.5th and 97.5th centiles) are presented in Figure $1, a-d$.

The median percentage of fetal body movements decreased curvilinearly from $17 \%$ at 24 wk to about $7 \%$ near term (Fig. 1a). The upper limit (97.5th centile) was high due to some outliers, but the lower limit (2.5th centile) hardly changed after 30 wk (2.5-4.0\%). The median number of fetal movement bursts per hour declined from 192 to 57 between 24 and 41 wk (Fig. 1b), whereas the mean duration of fetal body movements per recording remained fairly stable (3-4 s) in this period (Fig. 1c). An almost linear increase was found for the median onset-onset interval per recording, which changed from $9 \mathrm{~s}$ at $24 \mathrm{wk}$ to $15 \mathrm{~s}$ at $41 \mathrm{wk}$; the interfetal variability increased progressively with advancing gestational age, but the lower limit remained near 5-6 s (Fig. 1d). 
Fetal movement incidence in relation to FHRP A and B. A total of 237 recordings was available for analysis of fetal movement incidence in relation to FHRP.

Episodes of FHRP B were present in all of the 237 recordings. During these episodes, the percentage incidence and number of movements per hour were somewhat raised as compared with the results for total recording length, especially after 32 wk of gestation (Fig. 2, $a$ and $b$ ), but the decreasing trends with advancing gestational age were similar to those seen in the overall nomograms (Fig. 1, $a$ and $b$ ). Burst duration and the onset-onset interval of movements remained unchanged during FHRP B episodes.

Episodes of FHRP A were present in 148 out of 237 recordings, and the majority $(n=110)$ were seen after $32 \mathrm{wk}$. The median duration of episodes of FHRP A increased from $14.5 \mathrm{~min}$ (range $4.5-32.5 \mathrm{~min}$ ) at $32-34 \mathrm{wk}$ to $36.0 \mathrm{~min}$ (range $14.5-60.0 \mathrm{~min})$ at $38-40 \mathrm{wk}$. Those fetuses who had five or

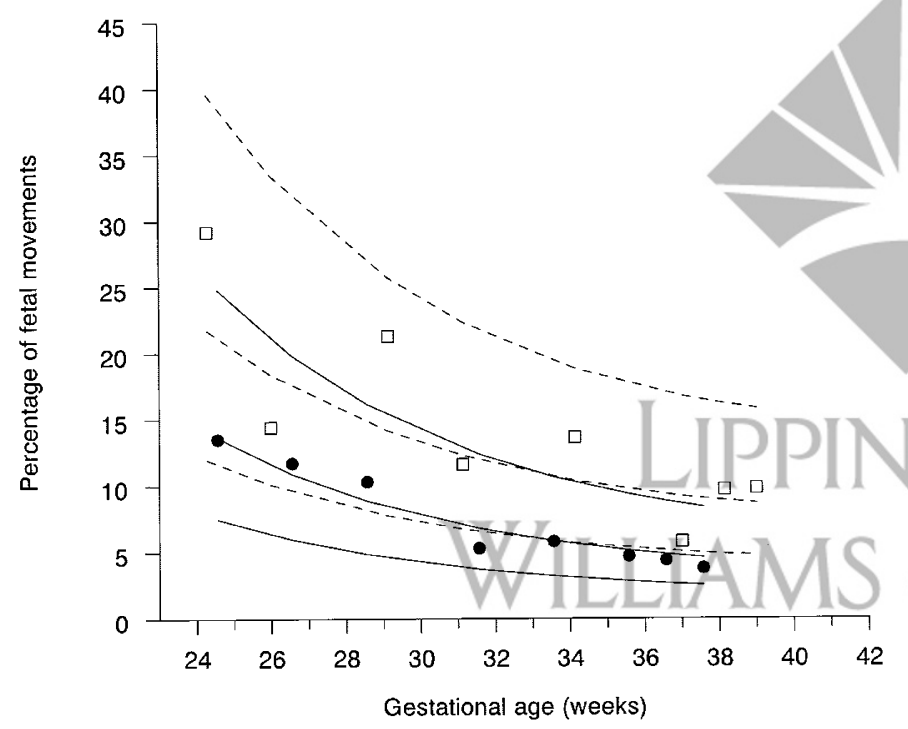

Figure 4. Regression lines of the percentage of body movements and $90 \%$ confidence interval of two fetuses with their individually measured values. The fetus represented by the solid line and the dots moved consistently less than the fetus represented by the dashed line and the open squares. more recordings with a FHRP A episode $(n=19)$ showed a decreasing trend over time for the percentage incidence and the number of movements per hour, with hardly any movements during FHRP A near term (Fig. 2, $c$ and $d$ ).

Intrafetal consistency. Individual regression lines generally showed the same trend throughout gestation for each of the movement parameters (Fig. 3, $a-d$ ). For instance, fetuses who moved during a relatively large or small percentage of time did so consistently throughout pregnancy (Fig. 3a), as is shown for two individual fetuses in Figure 4. These data suggest a rather homogeneous trend and level for each fetus, with intrafetal consistency and large interfetal differences with regard to the individually measured values. To quantify intrafetal consistency, we determined intrafetal (level 1) variance as the proportion of total variability, i.e. the sum of the inter- and intrafetal variances (Table 2). The proportion of the total range "used" by individual fetuses was considerable among the four movement parameters and ranged between $40 \%$ and $80 \%$ (Fig. 5 ). For the overall percentage incidence of body movements, the total range used was on average $56 \%$ (range $41-63 \%$ ) and $54 \%$ (range 37-62\%) for the percentage incidence during FHRP B. Interestingly, intrafetal consistency improved with advancing gestational age, except for the onset-onset intervals.

\section{DISCUSSION}

In contrast to previous studies $(7-15,18)$, we analyzed our longitudinally obtained fetal movement data in uncomplicated pregnancies using multilevel analysis. This technique has several advantages and is to be preferred compared with other methods of repeated measures analysis. It takes into account the dependency of measurements in the same fetus and the possible effect of confounding factors and it can deal with various frequencies of recording (35). Moreover, it allows for the identification of trends over time in individual fetuses and for assessment of intrafetal consistency. We developed normal reference ranges from $24 \mathrm{wk}$ of gestation onward for the percentage of time spent making body movements, the number of movements per hour, their duration, and onset-onset inter-

Table 2. Equations for the lines during fetal heart rate pattern $B$ of ${ }^{10} \log$ (percentage) and ${ }^{10} \log ($ number) with gestation, including interfetal and intrafetal variance

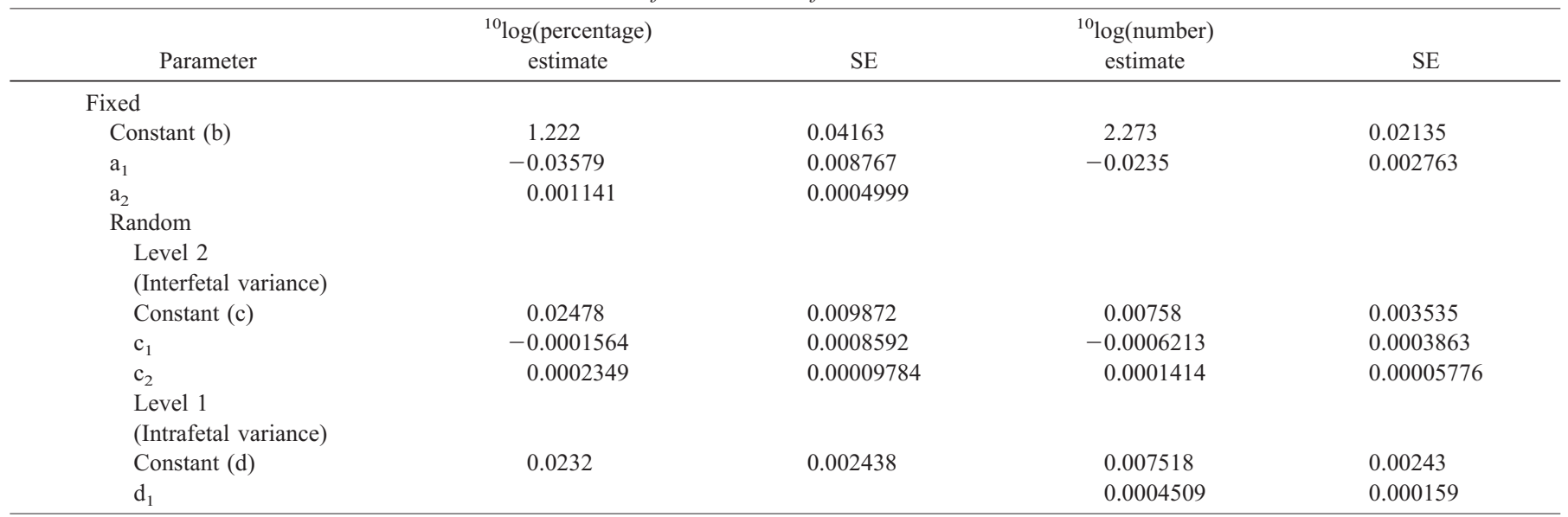

All equations must be read as $\mathrm{y}=\mathrm{b}+\mathrm{a}_{1}\left(\right.$ WGA-24) $+\mathrm{a}_{2}(\text { WGA-24) })^{2}$. The equation for the interfetal variance is $\mathrm{y}=\mathrm{c}+2 \mathrm{c}_{1}\left(\right.$ WGA-24) $+\mathrm{c}_{2}\left(\right.$ WGA-24) ${ }^{2}$. The equation for the intrafetal variance is $y=d+2 d_{1}($ WGA-24). SE, standard error; WGA, weeks gestational age. 


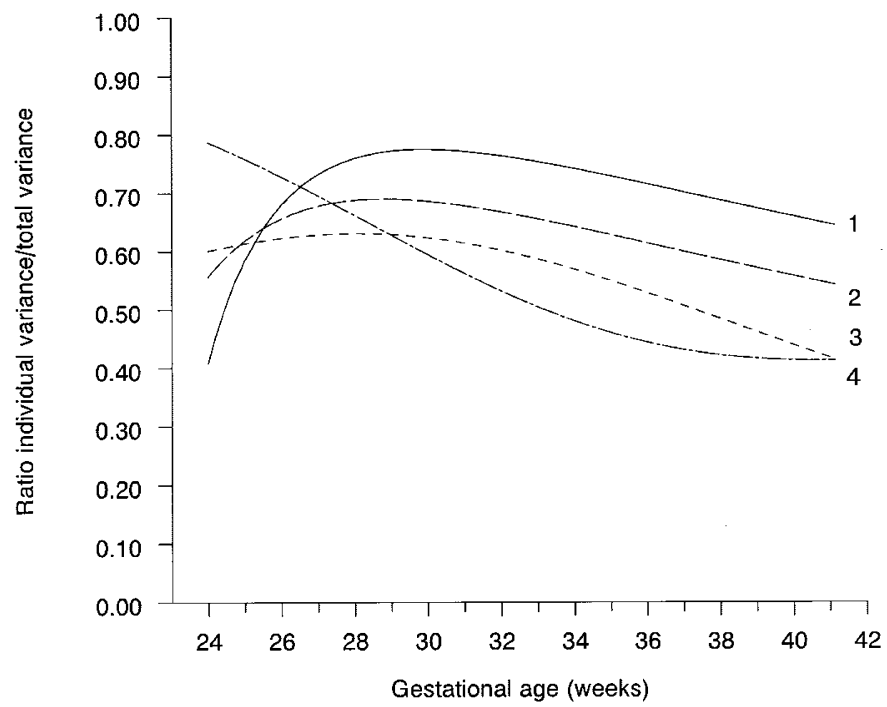

Figure 5. Intrafetal consistency with gestation presented as the ratio between intrafetal variance (level 1) and the total variability (sum of the intra- and interfetal variabilities) for 1) the median onset-onset interval; 2) the number of body movements per hour; 3) the percentage of body movements; and 4) the mean duration of body movements.

val (Fig. 1, $a-d$ ). The relatively stable duration of bursts of body movements throughout pregnancy combined with increasing duration of the intervals between successive bursts (onset-onset intervals) resulted in a decrease in the number of movements per hour. The concomitant decline of the percentage incidence of fetal body movements we found is in agreement with a number of previous studies $(7,10,14)$, although the reported values were either lower $(7,10)$ or higher (14) than the values we found. This difference in absolute values is probably due to differences in methodology, as described elsewhere (17).

In the present study, we found a gradual prolongation of episodes of fetal quiescence, as indicated by FHRP A. The median duration of FHRP A episodes increased from $14.5 \mathrm{~min}$ at 32-34 wk to $36.0 \mathrm{~min}$ at term, and a dramatic decline in fetal movements was seen during these episodes. These data are in line with those of others who investigated the gradual development of behavioral states during pregnancy $(36,38,44-46)$. However, the emergence of states and thus the emergence of longer episodes of fetal quiescence could not be held responsible for the overall decrease in fetal body movements, as the amount of movement during active episodes did not remain constant over time. Conversely, the developmental course for the four movement parameters during episodes of fetal activity, as indicated by FHRP B (Fig. 2, $a$ and $b$ ), appeared to be the same as those obtained for the total recording time. This demonstrates that the overall decline in movement incidence during pregnancy is a developmental phenomenon due to a change in movement parameters during FHRP $\mathrm{B}$ and to a lesser extent to the emergence of progressively increasing episodes of fetal quiescence (FHRP A) and to the gradual disappearance of fetal movements therein.

In preterm born infants ( $\geq 30$ wk of gestation), quiet sleep episodes can be recognized after birth from about $32 \mathrm{wk}$ of conceptional age onward (47). Body movements may occur frequently during these episodes before $34-36 \mathrm{wk}$, but are usually absent thereafter. In human fetuses, quiet episodes have also been observed at 30-32 wk with quite frequent interruptions of fetal quiescence by movements (38). A developmental trend of decreasing movement during FHRP A was also found for the fetuses in the present study. However, in some recordings there were still movement bursts present during quiet episodes at term age, which may be a sign of neurologic immaturity.

Low-risk preterm infants (born before 37 wk of gestation) also show decreased body movements with advancing age after birth, especially between 36 and 40 wk conceptional age as described by Prechtl et al. (48). They concluded that because this reduction occurred in both fetuses and preterm infants, intrauterine spatial constriction cannot be responsible. Instead, this phenomenon is more likely due to the development of inhibitory neural mechanisms.

The variance at levels 1 and 2, as calculated by multilevel analysis, are measures of intra- and interfetal consistency, respectively. The movement parameters appeared to be relatively consistent from 24 wk onward within the individual fetus (Fig. 3, $a-d$, and Fig. 4), with their range of spread being much lower than the overall range. On average, however, the intrafetal variance took up $40-80 \%$ of the total variance. The intrafetal variance for the percentage of fetal body movements took up $56 \%$ of the total variance (range $41-63 \%$ ). This relatively poor intrafetal consistency is in agreement with the $50 \%$ described by de Vries et al. (7) for the intrafetal variation in the percentage incidence of fetal movements. It also agrees with the large intraindividual variation in motor scores found in a longitudinal study of normally developing full-term infants (49). A greater intrafetal consistency has been suggested for fetal heart rate parameters $(15,50)$ and fetal behavioral state organization (51). In a previous study, concerning the same fetuses as presented in this study, we found that the intrafetal variance for fetal heart rate parameters only took up $19-55 \%$ of the total range of variance (19).

- The present study showed that large differences existed between the fetuses. The reason for the high intra- and interfetal variation is not clear at present, but could not be attributed to differences in recording time during daytime. In the literature, however, diurnal rhythms have been found to influence fetal activity $(8,12,52,53)$. This seeming discrepancy could be explained by the fact that we standardized for the time of recording within each fetus and that all recordings were performed during daytime, whereas fetuses have been described to be most active between 2100 and $0100 \mathrm{~h}(8,52)$. A possible effect of ultradian rhythms was unlikely as the intrafetal variance was still $56 \%$ (range $37-62 \%$ ) for the percentage incidence of movements during FHRP B.

Due to the high intrafetal variability, clinical decisions should not be based on the sole finding of a decrease in the quantity of fetal movements, but rather on a deviation from the individual course in serial measurements, as is done for fetal growth. When body movements decrease below the lower range of normality, however, this should be considered a warning and further investigations to assess fetal well being should be undertaken. 


\section{REFERENCES}

1. Lamb B, Lang R 1992 Aetiology of cerebral palsy. Br J Obstet Gynaecol 99:176-178

2. Manning FA, Platt LD, Sipos L 1979 Fetal movements in human pregnancies in the third trimester. Obstet Gynecol 54:699-702

3. Visser GHA, Mulder EJH, Prechtl HFR 1992 Studies on developmental neurology in the human fetus. Dev Pharmacol Ther 18:175-183

4. Prechtl HFR 1988 Developmental neurology of the fetus. Baillieres Clin Obstet Gynaecol 2:21-36

5. Prechtl HFR, Einspieler C 1997 Is neurological assessment of the fetus possible? Eur J Obstet Gynecol Repr Biol 75:81-84

6. Krasnegor NA, Fifer W, Maulik D, McNellis D, Romero R, Smotherman W 1998 Fetal behavioural development: a transdisciplinary perspective for assessing fetal well-being and predicting outcome. Prenat Neonat Med 3:185-190

7. de Vries JIP, Visser GHA, Prechtl HFR 1988 The emergence of fetal behaviour. III. Individual differences and consistencies. Early Hum Dev 16:85-103

8. Patrick J, Campbell K, Carmichael L, Natale R, Richardson B 1982 Patterns of gross fetal body movements over 24-hour observation intervals during the last 10 weeks of pregnancy. Am J Obstet Gynecol 142:363-371

9. Patrick J, Campbell K, Carmichael L, Natale R, Richarson B 1980 Patterns of human fetal breathing during the last 10 weeks of pregnancy. Obstet Gynecol 56:24-30

10. Natale R, Nasello Paterson C, Turliuk R 1985 Longitudinal measurements of fetal breathing, body movements, heart rate, and heart rate accelerations and decelerations at 24 to 32 weeks of gestation. Am J Obstet Gynecol 151:256-263

11. Roberts AB, Griffin D, Mooney R, Cooper DJ, Campbell S 1980 Fetal activity in 100 normal third trimester pregnancies. Br J Obstet Gynaecol 87:480-484

12. Nasello Paterson C, Natale R, Connors G 1988 Ultrasonic evaluation of fetal body movements over twenty-four hours in the human fetus at twenty-four to twenty-eigh weeks' gestation. Am J Obstet Gynecol 158:312-316

13. Bekedam DJ, Visser GHA, Mulder EJH, Poelmann Weesjes G 1987 Heart rate variation and movement incidence in growth-retarded fetuses: the significance of antenatal late heart rate decelerations. Am J Obstet Gynecol 157:126-133

14. Roodenburg PJ, Wladimiroff JW, van Es A, Prechtl HFR 1991 Classification and quantitative aspects of fetal movements during the second half of normal pregnancy. Early Hum Dev 25:19-35

15. Visser GHA, Goodman JDS, Levine DH, Dawes GS 1982 Diurnal and other cyclic variations in human fetal heart rate near term. Am J Obstet Gynecol 142:535-544

16. Devoe LD, Youssef AA, Castillo RA, Croom CS 1994 Fetal biophysical activities in third-trimester pregnancies complicated by diabetes mellitus. Am J Obstet Gynecol 171:298-303

17. ten Hof J, Nijhuis IJ, Nijhuis JG, Narayan H, Taylor DJ, Visser GH, Mulder EJ 1999 Quantitative analysis of fetal general movements: methodological considerations. Early Hum Dev 56:57-73

18. Ribbert LSM 1993 Assessment of fetal well-being in growth retardation. Ph.D. thesis, University of Groningen, Groningen, The Netherlands, pp 29-34

19. Nijhuis IJM, ten Hof J, Mulder EJH, Nijhuis JG, Narayan H, Taylor DJ, Westers P, Visser GHA 1998 Numerical fetal heart rate analysis: nomograms, minimal duration of recording and intrafetal consistency. Prenat Neonat Med 3:314-322

20. Nijhuis IJM, ten Hof J, Mulder EJH, Nijhuis JG, Narayan H, Taylor DJ, Visser GHA 1998 Fetal heart rate (FHR) parameters during FHR patterns A and B: a longitudinal study from 24 weeks' gestation. Prenat Neonat Med 3:383-393

21. Gardosi J, Mongelli M, Wilcox M, Chang A, Sahota D, Francis A 1997 Gestation related optimal weight (GROW) program. Software version 2. Nottingham, U.K., PRAM, University of Nottingham.

22. Wright KW 1995 Pediatric ophthalmology and strabismus. Mosby, St. Louis, MO, pp $310-312$

23. Visser GHA, de Vries JIP, Mulder EJH, Ververs IA, van Geijn HP 1993 Effects of frequent ultrasound during pregnancy [letter; comment]. Lancet 342:1359-1360

24. Stark CR, Orleans M, Haverkamp AD, Murphy J 1984 Short- and long-term ris after exposure to diagnostic ultrasound in utero. Obstet Gynecol 63:194-200

25. Reece EA, Assimakopoulos E, Zheng X-Z, Hagay Z, Hobbins JC 1990 The safety of obstetric ultrasonography: concern for the fetus. Obstet Gynecol 76:139-146
26. Kossoff G 1997 Editorial: Contentious issues in safety of diagnostic ultrasound. Ultrasound Obstet Gynecol 10:151-155

27. Anonymous 1976 Biological effects of ultrasonic energy on living mammals. Ultrasound Med Biol 2:351

28. Anonymous 1983 Safety statements. J Ultrasound Med 2(suppl):1-49

29. Anonymous 1988 Bioeffects consideration for the safety of diagnostic ultrasound. J Ultrasound Med 7(suppl):53-56

30. ECURS, Safety ECfUR 1995 EFSUMB Guidelines for the safe use of Doppler ultrasound for clinical applications. Eur J Ultrasound 2:167-168

31. de Vries JIP, Visser GHA, Prechtl HFR 1982 The emergence of fetal behaviour. I. Qualitative aspects. Early Hum Dev 7:301-322

32. Cohen J 1968 Weighted kappa: nominal scale agreement with provision for scaled disagreement or partial credit. Psychol Bull 70:213

33. Braakman R, Avezaat CJJ, Maas AIR, Roel M, Schouten HJA 1977 Interobserver and intraobserver variation in the assessment of antepartum cardiotocograms. J Obstet Gynecol 144:701-705

34. Prechtl HFR 1986 Prenatal motor development. In: Wade MG, Whiting HTA (eds) Motor Development in Children: Aspects of Coordination and Control. Nijhoff, Dordrecht, The Netherlads, pp 53-64

35. Goldstein H 1995 Multilevel Statistical Models, 2nd Ed. Kendall's Library of Statistics 3. University of London, London

36. Nijhuis JG, Prechtl HFR, Martin Jr CB, Bots RSGM 1982 Are there behavioural states in the human fetus? Early Hum Dev 6:177-195

37. Pillai M, James DK, Parker M 1992 The development of ultradian rhythms in the human fetus. Am J Obstet Gynecol 167:172-177

38. Visser GHA, Poelmann Weesjes G, Cohen TMN, Bekedam DJ 1987 Fetal behavior at 30 to 32 weeks of gestation. Pediatr Res 22:655-658

39. Nijhuis JG, van de Pas M 1992 Behavioral states and their ontogeny: human studies. Semin Perinatol 16:206-210

40. Nijhuis IJ, ten Hof J, Nijhuis JG, Mulder EJ, Narayan H, Taylor DJ, Visser GH 1999 Temporal organization of fetal behavior from 24 weeks' gestation onwards in normal and complicated pregnancies. Dev Psychobiol 34:257-268

41. Visser GHA, Dawes GS, Redman CW 1981 Numerical analysis of the normal human antenatal fetal heart rate. Br J Obstet Gynaecol 88:792-802

42. Drogtrop AP, Ubels R, Nijhuis JG 1990 The association between fetal body movements, eye movements and heart rate patterns in pregnancies between 25 and 30 weeks of gestation. Early Hum Dev 23:67-73

43. Mulder EJH, Visser GHA, Bekedam DJ, Prechtl HFR 1987 Emergence of behavioural states in fetuses of type-1-diabetic women. Early Hum Dev 15:231-251

44. Dierker Jr LJ, Pillay S, Sorokin Y, Rosen MG 1982 The change in fetal activity periods in diabetic and nondiabetic pregnancies. Am J Obstet Gynecol 143:181-185

45. Pillai M, James D 1990 Development of human fetal behavior: a review. Fetal Diagn Ther 5:15-32

46. Arduini D, Rizzo G, Giorlandino C, Valensise H, Dell'Acqua S, Romanini C 1986 The development of fetal behavioural states: a longitudinal study. Prenat Diagn 6:117-124

47. Dreyfus-Brisac C 1970 Ontogenesiš of sleep in human prematures after 32 weeks of conceptional age. Dev Psychobiol 3:91-121

48. Prechtl HFR, Fargel JW, Weinmann HM, Bakker HH 1979 Postures, motility and respiration of low-risk pre-term infants. Dev Med Child Neurol 21:3-27

49. Darrah J, Redfern L, Maguire TO, Beaulne AP, Watt J 1998 Intra-individual stability of gross motor development in full-tem infants. Early Hum Dev 52:169-179

50. Smith JH, Dawes GS, Redman CWG 1987 Low human fetal heart rate variation in normal pregnancy. Br J Obstet Gynaecol 94:656-664

51. Groome LJ, Bentz LS, Holland SB, Swiber MJ, Singh KP, Trimm RF 1995 Individual consistency in behavioral state profiles in human fetuses between 38 and 40 weeks gestation. J Matern Fetal Med 4:247-251

52. Roberts AB, Little D, Cooper D, Campbell S 1979 Normal patterns of fetal activity in the third trimester. Br J Obstet Gynaecol 86:4-9

53. de Vries JIP, Visser GHA, Mulder EJH, Prechtl HFR 1987 Diurnal and other variations in fetal movement and heart rate patterns at 20-22 weeks. Early Hum Dev $15: 333-348$ 